ISSN 1991-8631

Original Paper

http://indexmedicus.afro.who.int

\title{
Protective effects of the aqueous extract of Nymphaea lotus L. (Nymphaeaceae) against ethanol-induced gastric ulcers
}

\author{
Lucy B. JOHN-AFRICA*, Maryam S. IDRIS-USMAN, Bulus ADZU and \\ Karniyus S. GAMANIEL \\ Department of Pharmacology and Toxicology, National Institute for pharmaceutical Research and \\ Development, P.M.B 21, Garki, Abuja, Nigeria. \\ *Corresponding author; E-mail: lbjafrica@yahoo.com; Tel: +234(0)8058577557
}

\begin{abstract}
Effects of the aqueous extract of Nymphaea lotus were investigated on ethanol induced gastric lesions in rats. The extract $(250,500,1000 \mathrm{mg} / \mathrm{kg})$ significantly $(\mathrm{P}<0.05)$, dose dependently, protected the rat gastric mucosa against the necrotising effects of ethanol. Preliminary phytochemical screening of the extract revealed the presence of saponins, tannins, flavonoids, terpenes, and had an oral $\mathrm{LD}_{50} \mathrm{Of}>5000 \mathrm{mg} / \mathrm{kg}$. These results shows that aqueous extract of Nymphaea lotus contains active ingredients with a therapeutic potential against gastric ulcers, and thus authenticate the use of Nymphaea lotus as an antiulcer agent in traditional medicine. (C) 2012 International Formulae Group. All rights reserved.
\end{abstract}

Keywords: Nymphaeae lotus, ethanol-induced gastric ulcers, gastroprotection,

\section{INTRODUCTION}

Gastric ulcer is one of the most common diseases involving the gastrointestinal tract, which affects a considerable number of people in the world (Ganesan et al., 2010; Naseri et al., 2007). It is a disease with a complex aetiology that has not been fully understood (Mota et al., 2009). They are mucosal lesions that result from an imbalance between aggressive factors such as acid and pepsin, and defensive mechanisms like gastric mucous, high mucosal blood flow and high mucosal turnover rate that work towards maintenance of mucosal integrity (Nair et al., 2010). Its prevention and treatment is one of the major significant challenges confronting medicine (Calam and Baron, 2001). Plants have been used as valuable resources in the development of novel drugs, and many have shown potentials to be used in the treatment of gastric ulcers (Jainu et al., 2006). Such plant derived medicines are widely used because they are relatively safer than the synthetic medicines, readily available and considerably cheap (Yisa, 2009).

Nymphaea lotus L. (Nymphaeaceae) also known as water lily or 'bado' in Hausa belongs to a small family found in both temperate and tropical regions. They are easily recognised by their aquatic habit, floating leaves, flamboyant flowers, several petals, many stamens and carpels and endospermous seeds with small embryo (Hutchinson and Dalziel, 1954), and are an important food item among some African tribes. In Hausa land (Nigeria), the seeds are used medicinally for eruptive fevers while in Sierra Leone the leaf is used to prepare lotion for the eyes. A decoction of the leaf is also 
used as a narcotic or sedative. An infusion of the stem and roots is used as an emollient, diuretic or taken for urethral discharges (Dalziel, 1937). The plant is also used (fresh or dried and boiled) traditionally for the treatment of stomach ulcers (Hajia Hauwa Mohammed, personal communication).

The plant was reported to exhibit antimicrobial activity (Akinjogunla et al., 2009; Hassan et al., 2009; Yisa, 2009), and reported to contain phenolic compounds and antioxidant potential (Saleem et al., 2001), as well as toxicity and mutagenic actions (Sowewimo et al., 2007). Phytochemical analysis (Yisa, 2009) and studies on the plant's constituents (Saleem et al., 2001) have been carried out. Two unusual macrocyclic flavonoids have been isolated from Nymphaea lotus (Elegami et al., 2003).

Despite its popular traditional usage for the treatment of stomach ulcers, no scientific report of this plant on gastric ulcers has been provided in literature. This study was therefore designed to investigate the gastroprotective activity of the aqueous extract of the whole plant (including leaves but no seeds) of Nymphaea lotus.

\section{MATERIALS AND METHODS Plant material}

The leaves of Nymphaeae lotus (NL) were collected in the month of August 2009 around Kano city, Nigeria by Mallam I, Muazzam. The plant was identified and authenticated by Dr. jamila Ibrahim of the Taxonomy Unit, Department of Medicinal Plant Research and Traditional Medicine, National Institute for Pharmaceutical Research and Development (NIPRD) Idu, Abuja. A voucher specimen (No: NIPRD/H/6588) was deposited at the herbarium of the institute.

\section{Extraction}

The whole plant without the seeds of Nymphaea lotus were air-dried and pounded into coarse powder using mortar and pestle. $500 \mathrm{~g}$ of the powdered plant material was subjected to cold maceration in $3.0 \mathrm{~L}$ of water for $24 \mathrm{~h}$ with occasional shaking. This was filtered and the filtrate was concentrated in a rotary evaporator maintained at $70{ }^{\circ} \mathrm{C}$. The concentrate was dried over a water bath to give a solid (the extract) with a mean yield of $7.54 \pm 1.2 \% \mathrm{w} / \mathrm{w}$.

\section{Animals}

All experiments performed on laboratory animals in this study followed the National Institute for Health Guide for the Care and Use of Laboratory Animals (NIH Publications No 80-23), revised 1985 and NIPRD's Standard Operation Procedures on laboratory animal usage (NIPRD-SOPs no 05:3:06). Wistar rats $(200-250 \mathrm{~g})$ of both sexes, bred under uniform condition at the Animal Facility Centre, NIPRD, were used in this study. They were housed in standard polypropylene cages with saw dust as beddings, under normal condition of temperature $\left(25 \pm 2{ }^{\circ} \mathrm{C}\right), 12 \mathrm{~h}$ light/dark cycle and fed on standard feed and water ad libitum. In all experiments, the rats were fasted for 24 $\mathrm{h}$, but allowed free access to water to ensure an empty stomach during the experiment and prevent excessive dehydration during the fasting period (Garg et al., 1993).

\section{Phytochemical analysis}

The extract was subjected to phytochemical analysis for the presence of various constituents. It was screened for the presence of carbohydrates, tannins, glycosides, flavonoids, saponins, anthraquinones, and alkaloids according to standard methods (Odebiyi and Sofowora, 1978).

\section{Acute toxicity studies}

Rats of both sexes (200 - $250 \mathrm{~g})$ were used for this test following the modified Lorke's (1983) method. This test was carried out in two phases. The drug was administered orally to healthy fasted rats through single bolus dose of plant extract using an orogastric cannula. In the first phase, animals were randomly placed in three groups of 3 animals each. Each group was administered geometric doses 10,100 and $1000 \mathrm{mg} / \mathrm{kg}$ of the extract respectively. The animals were observed for physical signs of intoxication; the severity, onset and progression for a period of $24 \mathrm{~h}$. 
The second stage of dosing was scheduled based on the observations recorded in stage one. In the second stage, 3 groups of 3 animals each were given 1600, 2900 and 5000 $\mathrm{mg} / \mathrm{kg}$. All animals were observed for a period of 7 days. The median lethal dose $\left(\mathrm{LD}_{50}\right)$ was estimated from the second stage of dosing. These were observed for signs of toxicity and mortality. The $\mathrm{LD}_{50}$ was calculated using the formula:

$\mathrm{LD}_{50}=\sqrt{ }$ lowest lethal dose $\mathrm{X}$ highest non lethal dose.

\section{Anti-ulcer studies}

\section{Studies on ethanol-induced gastric ulcers}

The rats were randomized and divided into five groups of six rats each and treated as described below:

Group 1: Vehicle (distilled water) and served as control

Group 2: Omeprazole (100 mg/kg, p.o.)

Groups 3-5: NL extract (250, 500 and 1000 $\mathrm{mg} / \mathrm{kg}$, p.o.) respectively

After $1 \mathrm{~h}$ each rat received $0.5 \mathrm{ml} / 100 \mathrm{~g}$ body weight absolute ethanol (ulcerogen).

Studies on the preventive, curative and cytoprotective effects of Nymphaea lotus extract

Fasted rats were randomised and placed in groups of six rats each and treated as follows:

Group 1: Distilled water.

Group 2: NL $1000 \mathrm{mg} / \mathrm{kg}, 1 \mathrm{~h}$ before the administration of $0.5 \mathrm{ml} / 100 \mathrm{~g}$ of absolute ethanol (preventive treatment).

Group 3: NL extract (1000 mg/kg, p.o.) 15 min after administration of the ulcerogenic agent (curative treatment).

Group 4: Indomethacin (20 mg/kg s.c) $1 \mathrm{~h}$ before ethanol. The extract NL $1000 \mathrm{mg} / \mathrm{kg}$ was given $30 \mathrm{~min}$ after Indomethacin administration

Group 5: NL extract (1000 mg/kg, p.o.) followed by ethanol $(1.0 \mathrm{ml} / 100 \mathrm{~g}$ body weight, p.o. /rat) $1 \mathrm{~h}$ after extract administration.

Studies on the duration of action of Nymphaea lotus extract

In order to estimate the duration of action of the extract, normally fed rats were pre-treated with the extract at a dose of 1000 $\mathrm{mg} / \mathrm{kg}$ at $24 \mathrm{~h}, 48 \mathrm{~h}, 72 \mathrm{~h}$ and $96 \mathrm{~h}$ before administration of the ulcerogenic agent. The animals were fasted $24 \mathrm{~h}$ before ethanol administration.

All animals were sacrificed $1 \mathrm{~h}$ after ethanol administration by diethylether inhalation. The stomach was excised, cut along the greater curvature, and gently rinsed under a slow running tap. The stomach was stretched on a piece of cork with mucosal surface up for macroscopic examination. Scoring of ulcer was performed with the help of magnifying glass according to the scoring scale of Magistretti et al. (1988); the sum of the total severity of scores in each group of rats divided by the number of animals was expressed as the mean ulcer index (UI) and the curative ratio was calculated following the following formula:

$$
\begin{aligned}
\text { Curative ratio }= & \frac{(\text { C. T. I. })-(\text { T. U. I. })}{(\text { Control Ulcer Index })} \text { X } 100 \\
\text { where } & \begin{aligned}
\text { C. T. I. }=\text { Control Test Index } \\
\text { T. U. I. }=\text { Test Ulcer Index })
\end{aligned}
\end{aligned}
$$

Representative sample of the observations were documented photographically.

\section{Statistical Analysis}

Results were expressed as mean \pm SEM and the individual data were subjected to oneway analysis of variance (ANOVA) followed by Dunnet's post hoc test. Results were regarded as significant at $\mathrm{P}<0.05$.

\section{RESULTS}

Preliminary phytochemical screening revealed the presence of terpenes, flavonoids, tannins, sterols, carbohydrates, resins, saponins, and anthraquinones. The oral $\mathrm{LD}_{50}$ was greater than $5000 \mathrm{mg} / \mathrm{kg}$. Oral administration of absolute ethanol produced multiple mucosal lesions mainly in the glandular portion of the rat stomach. Pretreatment with Nymphaea lotus inhibited the ethanol-induced gastric mucosal injury in rats. Administration of single oral doses of Nymphaea lotus 250, 500 and $1000 \mathrm{mg} / \mathrm{kg}$ dose dependently reduced the ulcer index compared to distilled water with curative ratio of $28.33,38.33$ and 86.17 respectively. 
Omeprazole also significantly inhibited ethanol-induced gastric lesions $(\mathrm{P}<0.05)$. Ulcer index (UI) is shown in Table 1. When rat were pre-treated with $1000 \mathrm{mg} / \mathrm{kg}$ of the extract ulcer index was reduced to 0.85 , $\mathrm{P}<0.05$, compared to control UI 6.00 (Table 2 ). Acute administration of this same dose as a curative increased the ulcer index (3.80, $\mathrm{P}<0.05)$. When the quantity of ethanol was increased to $1 \mathrm{ml} / 100 \mathrm{~g}$ for a situation where severe damage is expected the extract still exhibited significant $(3.00, \mathrm{P}<0.05)$ protective effects. Preventive administration of single dose of Nymphaea lotus showed a reduction in gastric hyperaemia and decreased the number and severity of the lesions; an effect which persisted for up to $48 \mathrm{~h}$ after administration (Table 3). However this preventive effect of NL was reversed by pre-treatment with indomethacin.

Figure 1 (A, B, C, D) presents the representative stomachs showing the effect of Nymphaea lotus extract on ethanol induced gastric lesions in rats.

Table 1: Effect of Nymphaea lotus (NL) extract on ethanol induced gastric ulcers.

\begin{tabular}{lccc}
\hline Treatment & Dose $(\mathbf{m g} / \mathbf{k g})$ & Ulcer Index & Curative Ratio \\
\hline Distilled water & - & 6.00 & - \\
Omeprazole & 100 & $1.00 \pm 0.63^{*}$ & 83.33 \\
NL & 250 & $4.30 \pm 0.55^{*}$ & 28.33 \\
NL & 500 & $3.20 \pm 0.52^{*}$ & 46.67 \\
NL & 1000 & $0.83 \pm 0.41^{*}$ & 86.17 \\
\hline \multicolumn{2}{r}{ Each value expressed as mean \pm S.E.M. n=6; Significance difference between control groups *P $<0.05}$.
\end{tabular}

Table 2: Effect of Nymphaea lotus (NL) extract on ethanol-induced gastric ulcers.

\begin{tabular}{lccc}
\hline Treatment & Dose $\mathbf{( m g / k g )}$ & Ulcer Index & Curative Ratio \\
\hline Distilled water & - & 6.00 & - \\
NL (preventive) & 1000 & $0.85 \pm 0.45^{*}$ & 85.83 \\
NL (curative) & 1000 & $4.50 \pm 0.53^{*}$ & 25.00 \\
NL ( cytoprotective) & 1000 & $4.00 \pm 0.63^{*}$ & 33.33 \\
NL (severe damage) & 1000 & $3.00 \pm 0.63^{*}$ & 50.00
\end{tabular}

Each value expressed as mean \pm S.E.M. $\mathrm{n}=6$; Significance difference between control groups $* \mathrm{P}<0.05$.

Table 3: Duration of action of Nymphaea lotus (NL) extract on ethanol-induced gastric ulcers.

\begin{tabular}{lcc}
\hline Treatment (mg/kg) & Time (h) & Ulcer Index \\
\hline NL 1000 & 24 & $2.7 \pm 0.52^{*}$ \\
NL 1000 & 48 & $4.0 \pm 0.89^{*}$ \\
NL 1000 & 72 & $5.2 \pm 0.53$ \\
NL 1000 & 96 & $5.7 \pm 0.52$ \\
\hline
\end{tabular}

Each value expressed as mean \pm S.E.M. $n=6$; Significance difference between control groups $* \mathrm{P}<0.05$. 
L. B. JOHN-AFRICA et al. / Int. J. Biol. Chem. Sci. 6(5): 1917-1925, 2012

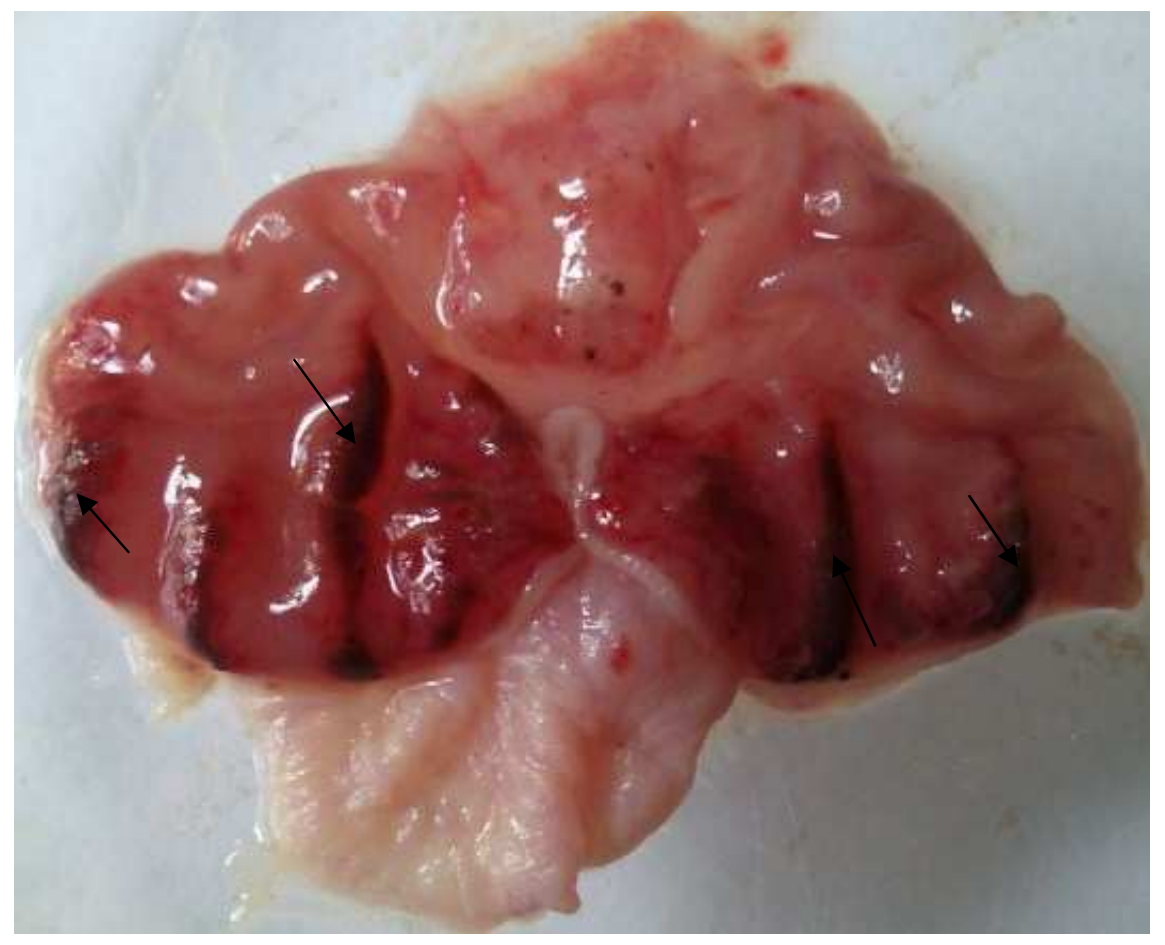

(A) Control (Distilled water + ethanol).

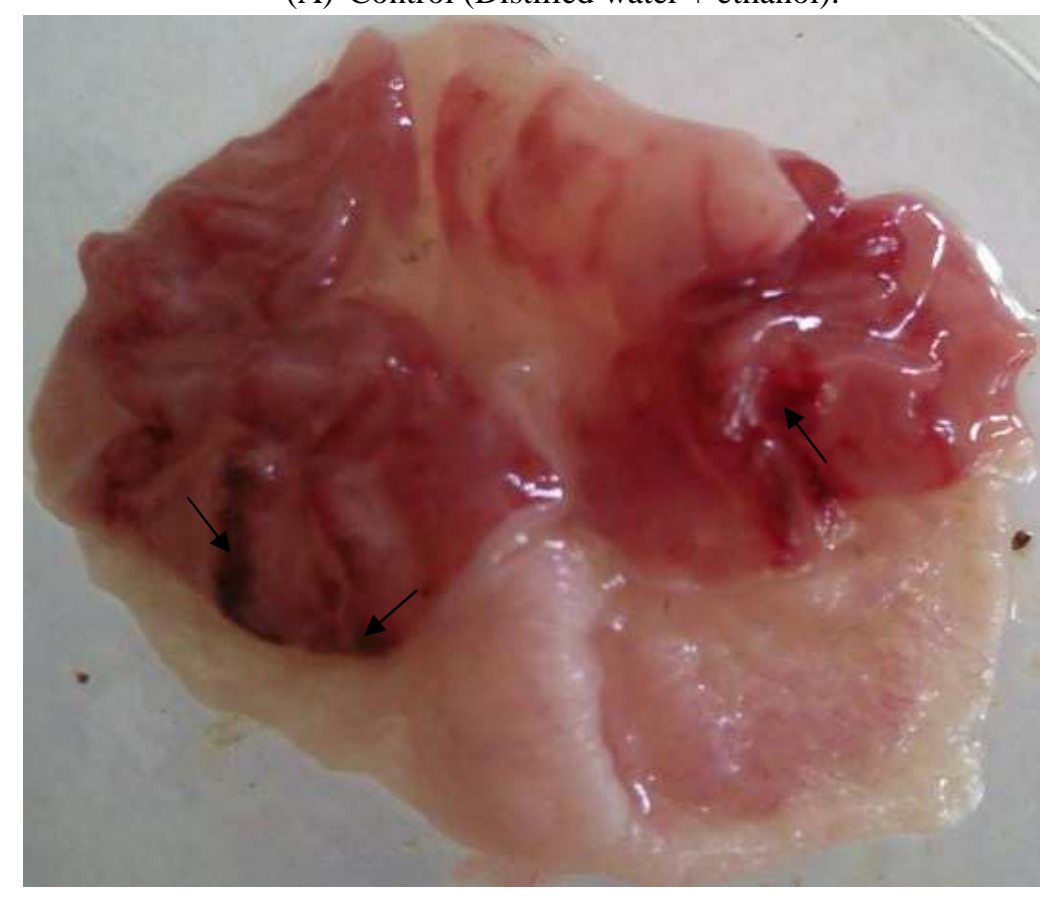

(B) $\mathrm{NL} 250 \mathrm{mg} / \mathrm{kg}+$ Ethanol. 


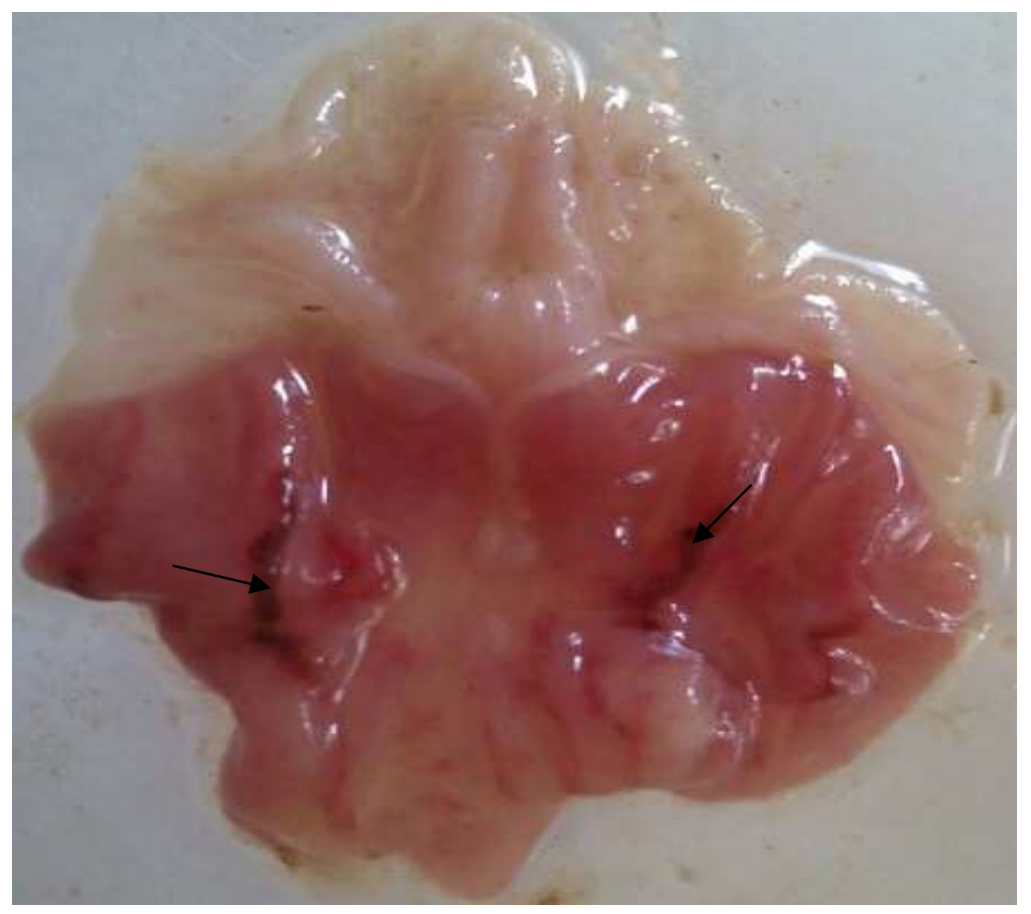

(C) $\mathrm{NL} 500 \mathrm{mg} / \mathrm{kg}+$ ethanol.

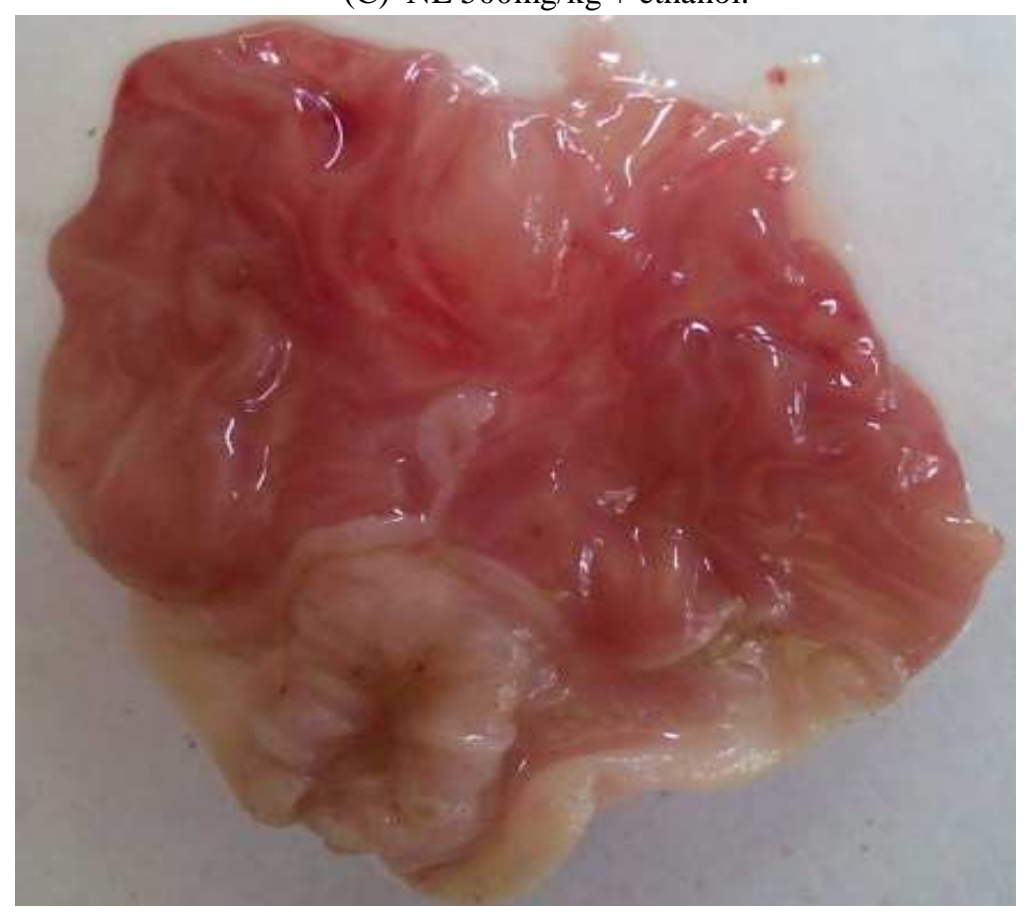

(D) NL 1000 mglkg + Ethanol.

Figure 1: (A, B, C, D) Representative stomachs showing the effect of Nymphaea lotus extract on ethanol induced gastric lesions in rats (arrows show gastric lesions). 


\section{DISCUSSION}

Intragastric application of absolute ethanol is a widely used reproducible method to induce gastric lesions in experimental animals. In this model the gastric damage produced is a consequence of a direct damage of gastric mucosal cells probably by the development of free radicals which leads to hyperoxidation of lipid (Khazaei and Salehi, 2006). Many other interrelating features such as increase in the release of 5hydroxytryptamine and histamine, increased free radical generation, leukotrienes production and ischemia and increased gastric vascular permeability, increased sodium and potassium efflux, increased calcium influx, decreased production of prostaglandin, gastric mucous, reduced mucosal blood flow and gastric motility have been implicated in this model. Each of which can be considered a potential therapeutic target such that the model can be a representation of human gastric ulcer disease (Galvin and Szabo, 1992). In this study, administration of absolute alcohol by gastric gavage induced marked damage to the gastric mucosa that was obvious by macroscopic examination. The lesions were extended haemorrhage predominantly in the glandular portion of the stomach. The administration of Nymphaea lotus significantly and dose dependently prevented the induction of acute gastric mucosal injury induced by absolute ethanol. Saleem et al. (2001) reported the inhibition of lipid peroxidation property of Nymphaea lotus extract. It is thus possible that the antioxidant property of the extract maybe counteracting oxidative damage caused by alcohol. This antioxidant effects appears to contribute to the observed anti ulcer activity.

Ethanol induced gastric ulcer model is used to test drugs for cytoprotection (Raju et al., 2009). Robert et al. (1983) proposed the term cytoprotection to relate to the ulcer reducing effect of prostaglandins by a mechanism which is independent inhibition of gastric secretion. Cytoprotection may occur as a result of the capacity that some compounds possess to induce prostaglandin production, fundamental for mucus protection, because they stimulate mucus and bicarbonate synthesis while strengthening gastric mucosal barrier (Nwidu and Nwafor, 2009). Pretreatment with indomethacin suppressed the preventive effect of the extract against ethanol. Indomethacin, an inhibitor of prostaglandin synthetase (Okokon and Nwafor, 2009), the enzyme accountable for the biosynthesis of prostaglandin, reduces the synthesis of prostaglandin and bicarbonate secretion and gastric mucosal blood flow in animals, thereby increasing susceptibility of the stomach to mucosal injury and gastroduodenal ulceration. When the antiulcer activity of an anti-ulcer agent is significantly reduced by pre-treatment with indomethacin, it can be translated that the agent is acting via the mediation or mobilization of endogenous prostaglandins; therefore the effects of the extract of Nymphaea lotus observed in this study may be interpreted in the same manner (Tan et al., 2000). The present results demonstrate that Nymphaea lotus protects gastric mucosa from acute gastric mucosal injury probably through the mobilization of endogenous prostaglandins.

Phytochemical screening revealed the presence of tannins, saponins, alkaloids and flavonoids. The medicinal properties of many plants are ascribed to the presence of phytochemical compounds such as flavonoids, alkaloids, terpenoids, tannins, phenolic acids and antioxidant micronutrients (Mota et al., 2009). Flavonoids inhibit gastric secretion and protect against experimental ulcer while the action of saponins as an anti ulcer agent is via the creation of protective mucous on the gastric mucosa (Guaraldo et al., 2001) and have been reported to help in the regulation of microcirculation which plays a role in the protective mechanism of the gastric mucosa 
(Galati et al, 1997). It is therefore possible to theorize the involvement of saponins in the protective effect of Nymphaea lotus as ethanol causes solubilisation of mucous constituents and depresses tissue levels of proteins leading to flow stasis in gastric blood (Galati et al., 2001). Nymphaea lotus may act to regulate microcirculation thereby enhancing mucosal blood flow. Tannins possess protein precipitating and vasoconstricting properties which could be beneficial in preventing ulcer occurrence. Tannins also possessing astringent properties may have precipitated microproteins on the site of ulcer resulting in the formation of an impermeable protective pellicle over the lining to prevent absorption of toxic substances and resist the attack of proteolytic enzymes (Nwafor et al., 2000; Abdulla et al., 2010). The presence of flavonoids, saponins and tannins in Nymphaea lotus acting synergistically could be contributory factors to the protection of gastric mucosa against the ulcerogen as observed in this study. The $\mathrm{LD}_{50}$ is greater than $5 \mathrm{~g} / \mathrm{kg}$ oral in rats is an indication of the safety of the extract.

In conclusion, this study authenticates the use of Nymphaea lotus as an antiulcer agent in traditional medicine although the exact mechanism of the gastroprotective action is not evident from the data available. Further studies are being carried out to determine the active principles and other mechanisms of action involved using different experimental models.

\section{REFERENCES}

Abdulla MA, Ahmed KA, AL-Bayaty FH, Masood Y. 2010. Gastroprotective effect of Phyllanthus niruri leaf extract against ethanol-induced gastric mucosal injury in rats. Afri J Pharma Pharmaco., 4: 226230.

Akinjogunla OJ, Adegoke AA, Udokang IP, Adebayo-Tayo BC. 2009. Antimicrobial potential of Nymphaea lotus
(Nymphaeaceae) against wound pathogens. J. Med. Plants Res., 3: 138141.

Calam J, Baron JH. 2001. Pathophysiology of duodenal and gastric ulcer and gastric cancer. Bri. Med. J., 323: 980-983.

Dalziel JM. 1937. The Useful Plants of West Tropical Africa. The Crown Agents: London.

Elegami AA, Bates C, Gray AI, Mackay SP, Skellern GG, Waigh RD. 2003. Two very unusual macrocyclic flavonoids from the water lily Nymphaea lotus Phytochemistry., 63: 727-731.

Galati EM, Sanogo R, Tzakou O, Rossito A, Germano PM. 1997. Antiulcerogenic Activity of Teucrium divaricatum Heldr.ssp. divaricatum Herdr. Ssp divaricatum. Phytother Res., 11: 572 575.

Galati EM, Monforte MT, Tripodo MM, D’Áquino A, Mondello MR. 2001. Antiulcer activity of Opuntia ficus indica (L) Mill. (Cactaceae): ultrastructural study. J. Ethnopharmacol., 76: 1-9.

Galvin GB, Szabo S. 1992. Experimental gastric mucosal injury: laboratory models reveal mechanisms of pathogenesis and new therapeutic strategies. Fed Am. Soc. Exp. Biol. J. 6: 825-831.

Ganesan B, Yathavamoorthi R, Sabeena Fravin FH, Anandan R. 2010. Supplementation of betaine attenuates $\mathrm{HCl}$-Ethanol induced gastric ulcers in rats. Int. J. Biol. Chem., 4: 79-89.

Garg GP, Nigam SK, Jr Ogle CW. 1993. The Gastric anti ulcer effect of the leaves of the Neem tree. Planta Medica., 59: 215217.

Guaraldo L, Sertie JA, Bachi EM. 2001. Anti-ulcer action of the hydroalchoholic extract and fractions of Davilla rugosa Poiret in the rat. J. Ethnopharmacol., 76: 191-195.

Hassan A, Rahman S, Deeba F, Mahmud S. 2009. Antimicrobial activity of some 
plant extracts having hepatoprotective effects. J. Med. Plants Res., 3: 20-23.

Hutchinson J, Dalziel JM. 1954. Flora of West Africa. The Crown agents for Colonies: London.

Jainu M, Vijai Mohan K, Shyamala Devi CS. 2006. Gastroprotective effect of Cissus quadrangularis extract in rats with experimentally induced ulcer. Ind. $J$. Med. Res., 123: 799-806.

Khazaei M, Salehi H. 2006. Protective effect of Falcaria vulgaris extract on ethanol induced gastric ulcer in rat. Iran. J. Pharmacol. Ther., 5: 43-46.

Lorke D. 1983. A new approach to acute toxicity testing. Archive of Toxicology, 54: 275-287.

Magistretti MJ, Conti M, Cristoni A. 1988. Antiulcer activity of an anthocyanidin from vaccinum myrtillus. Arzneimittel Forschung Drug Res., 38:686 - 690.

Mota KSL, Dias GEN, Pinto MEF, LuizFerreira A, Souza-Brito ARM, HirumaLima CA, Barbosa-Filho JM, Batista LM. 2009. Flavonoids with gastroprotective activity. Molecules., 14: 979-1012.

Nair V, Arjuman A, Gopalakrishna HN, Dorababu P, Mirshad PV, Bhargavan D, Chatterji D. 2010. Evaluation of the antiulcer activity of NR-ANX-C (a polyherbal formulation) in aspirin and pyloric ligature induced gastric ulcers in albino rats. Ind. J. Med. Res., 132: 218223.

Naseri MKG, Mard SA. 2007. Gastroprotective effect of Alhagi maurorum on experimental gastric ulcer in rats. Pak. J. Med. Sci., 23: 4.

Nwafor PA, Okwuasaba FK, Binda LG. 2000. Anti-diarrhoeal and anti-ulcerogenic effects of methanolic extract of Asparagus pubescens root in rats. $J$. Ethnopharmacol., 72: 21 - 427.
Nwidu LL Nwafor PA. 2009. Gastroprotective effects of leaf extracts of Carpolobia lutea (polygalaceae) G. Don. in rats. Afr. J. Biotech., 8: 012-019.

Odebiyi OO, Sofowora EA. 1978. Phytochemical screening of Nigerian medicinal plants. Lloydia. 41: 234.

Okokon JE, Nwafor PA. 2009. Antiulcer and anticonvulsant activity of Croton zambesicus. Pak J. Pharm. Sci., 22: 84390.

Raju D, Ilango K, Chitra V, Ashish K. 2009. Evaluation of Anti-ulcer activity of methanolic extract of Terminalia chebula fruits in experimental rats. J. Pharm. Sci. Res., 1: 101-107.

Robert A, Nezamis JE, Lancaster C, Davis JP, Field SO, Hanchar AJ. 1983. Mild irritants prevent gastric necrosis through "adaptative cytoprotection" mediated by prostaglandins. Am. J. Physiol., 245: G113-G121.

Saleem A, Ahotupa M, Pihlaja K. 2001. Total phenolics concentration and antioxidant potential of extract of medicinal plants of Pak. Z. Naturoforsch. C., 56: 973-978.

Sowemimo AA, Fakoya FA, Awopetu I, Omobuwajo OR, Adesanya SA. 2007. Toxicity and mutagenic activity of some selected Nigerian plants. $J$. Ethnopharmacol., 113: 427-432.

Tan PV, Penlap VB, Nyasse B, Nguemo JDB. 2000. Anti-ulcer actions of the ark of methanol extract of Voacanga africana in different experimental ulcer model in rats. J. Ethnopharmacol., 73: 432-428.

Yisa J. 2009. Phytochemical analysis and antimicrobial activity of Scoparia Dulcis and Nymphaea Lotus. Aust J. Basic Applied Sci., 3: 3975-3979. 